\title{
Central Nervous System Infections in Childhood - International Review of Child Neurology Series: Pratibha Singhi, Diane E Griffin, Charles R Newton (eds)
}

\author{
Published by Mac Keith Press, London, 2014; ISBN: 978-1-909962-44-6; Pages: 390; Price \\ (Hardcover): \$ 159.95
}

Satinder Aneja ${ }^{1}$

Received: 25 March 2015 / Accepted: 30 March 2015 /Published online: 8 May 2015

(C) Dr. K C Chaudhuri Foundation 2015

Infections of central nervous system remain an important cause of mortality and neurodisability among children. Reduction in long term morbidity from these infections is dependent on rapid diagnosis and prompt initiation of specific and supportive treatment. There has been significant progress in diagnostic techniques and therapeutic modalities in the last decade in this field. This book fills a void in the currently available material on central nervous system (CNS) infections in childhood. It is a multi-authored book ably edited by eminent Pediatric Neurologists. The contributors are scientists and researchers with great experience in CNS infections.

The first four chapters on epidemiology, pathogenesis and principles of management are exceptionally well written and lay the general concept of mechanism of infection and consequent pathology. There is a detailed account of common CNS infections caused by viruses, bacteria, fungi, rickettsia and parasites. There is emphasis on tropical diseases with chapters on rabies, tetanus and neurocysticercosis which would be of great help to Pediatricians and Infectious Disease experts. The book also includes post infectious disorders and imaging in CNS infection. There are 22 chapters in all; all of which have been well written. The editors have done a commendable job in keeping a very reader friendly and uniform format. The text is suitably supported with tables, figures and algorithms. There are very few color plates but there are plenty of good quality black and white photographs and neuroimaging pictures.

Considering the burden of congenital and neonatal infections, the chapter on congenital infections deserved more details. The authors should have included a chapter on practical microbiological aspects and newer diagnostic techniques of CNS infections. The chapter on febrile seizures appears out of place especially since there is hardly any discussion on role on infections in this chapter.

This book provides a concise overview of current knowledge of common CNS infections. The book is published by International Child Neurology Association as International Reviews of Child Neurology Series. The listed price of hardcover book makes it an expensive buy for physicians in resource poor countries. It is heartening to note that the editors intend to provide periodic updates to the electronic version of the book. The book will be certainly useful for pediatricians, infectious disease specialists and post-graduate students.

Satinder Aneja

drsaneja@gmail.com

1 Department of Pediatrics, Lady Hardinge Medical College \& Kalawati Saran Children Hospital, New Delhi 110001, India 